\title{
Serum eosinophilic cationic protein may predict clinical course of wheezing in young children
}

\author{
J R Villa, G García, S Rueda, A Nogales
}

\begin{abstract}
Thirty eight children aged between 2 and 4 years with three or more episodes of wheezing were studied to evaluate the role of eosinophil inflammation and its relation to persistence of wheezing two years later. Serum eosinophilic cationic protein, total eosinophil count, total IgE, skin prick test, and clinical features were evaluated at visit 1 . Two years later at a second clinical evaluation the children were separated into two groups: group 1, those with persistent wheezing $(n=20)$; group 2 , those who had been asymptomatic over the past six months (transient wheezing) $(n=18)$. Mean (SEM) eosinophilic cationic protein at visit 1 was higher in group 1 than in group $2(29.63(5.16) v 14.42$ (2.77) $\mu \mathrm{g} / \mathrm{l})$, and the probability of continuing wheezing at age 5 years was greater in children with values $\geqslant 20 \mu \mathrm{g} / 1$ at visit 1 than in those with lower values (relative risk $=2.88,95 \%$ confidence interval 1.42 to $5.87, \mathrm{p}<0.001$ ). Eosinophil inflammation is present from the beginning of the disease in the children who are going to continue with wheezing at age 5 years. The measurement of serum eosinophilic cationic protein may help in evaluating which wheezing infants are going to continue with asthma in the future.

(Arch Dis Child 1998;78:448-452)
\end{abstract}

Keywords: eosinophil cationic protein; childhood asthma; wheezing

It is accepted that asthma is a chronic inflammatory disease of the airways in which eosinophil cells play an important role. ${ }^{1}$ Performance of lung biopsies and bronchoalveolar lavage in adult asthmatic patients has permitted a better understanding of the pathogenic mechanisms involved. ${ }^{2}$ These studies have shown the importance of the inflammatory response in asthma and have profoundly changed the way asthma is treated, such that anti-inflammatory drugs are now recommended as first line treatment. ${ }^{34}$ However, as very few studies have evaluated these pathogenic features in children, and those that have have mostly been in older children, ${ }^{5}$ we cannot assume that the same inflammatory processes play the central role in asthma in young children. ${ }^{67}$ Recently, investigators have been considering the possibility of changing the natural course of asthma by aggressive antiinflammatory treatment during the initial phases of airway inflammation.
Asthma generally starts during the first years of life. However, young wheezing children are a heterogeneous group. About $60 \%$ of early wheezers suffer transitory disease and become asymptomatic when they reach 5-6 years of age, with only $40 \%$ continuing with asthma at this age. Children who have transitory wheezing during infancy have lower indices of pulmonary function measured at birth than the children with persistent wheezing. ${ }^{8}$ It has been shown that children with severe asthma and those with atopy ${ }^{10}$ are the ones who will continue with asthma when they reach adulthood. Identifying infants who will go on to develop persistent wheezing, and determining whether inhaled anti-inflammatory drugs ${ }^{11}$ or other treatments ${ }^{12}$ can block the processes leading to chronic asthma are important challenges in the prevention of this common disease. ${ }^{13}$

The possibility of determining serum and urinary markers of activity of the cells responsible for bronchial inflammation has made evaluating inflammation much easier in children. ${ }^{14}$ Of these markers, eosinophilic cationic protein is among the most studied. ${ }^{15}$ Eosinophilic cationic protein is a specific protein liberated by eosinophil cells when they are activated. There is a good correlation between concentrations of this protein in serum and in bronchoalveolar lavage fluid in adults, ${ }^{16}$ although this has not been studied in children. Airway function and bronchial hyperresponsiveness also have significant though weak correlations with serum eosinophilic cationic protein. ${ }^{17}$ Serum concentrations of the protein do not correlate directly with the peripheral blood eosinophil count but with the activity of these cells. ${ }^{18}$ Some studies have suggested that serum eosinophilic cationic protein may be a useful measure of both eosinophil activation and airway inflammation of children with asthma. ${ }^{19} 20$ There is little information, however, about the role of eosinophils and their mediators in wheezing illness during infancy. ${ }^{21}$

Our study was designed to evaluate the importance of eosinophilic inflammation in wheezing children in the first years of life, and to identify factors at onset of the diseaseincluding measurement of serum eosinophilic cationic protein as a marker of eosinophilic inflammation - that may predict the persistence of wheezing at age 5 years.

\section{Methods}

PATIENTS

Study participants were outpatients between 2 and 4 years of age who came to our centre with a clinical history of wheezing (defined as three or more episodes of wheezing before visit 1) 
Table 1 Clinical and laboratory characteristics of persistent wheezers (group 1) and transient wheezers (group 2) at visit 1

\begin{tabular}{llll}
\hline & Group 1 $(n=20)$ & Group 2 $(n=18)$ & p value \\
\hline Male/female & $12 / 8$ & $12 / 6$ & \\
Atopic dermatitis & $4 / 20$ & $7 / 18$ & \\
Food allergy & $5 / 20$ & $1 / 18$ & 0.1 \\
Asthmatic mother & $4 / 20$ & $0 / 18$ & \\
Asthmatic father & $2 / 20$ & $1 / 18$ & \\
Initial severity moderate & $12 / 20$ & $8 / 18$ & \\
Positive prick test & $9 / 20$ & $6 / 18$ & \\
Mean (SEM) total IgE (IU/ml) & $109.7(57.78)$ & $125.08(73.33)$ & $<0.01$ \\
Mean (SEM) serum ECP $(\mu \mathrm{g} / \mathrm{l})$ & $29.63(5.16)$ & $14.42(2.77)$ & 0.09 \\
Mean (SEM) total eosinophil count & $358.36(90.07)$ & $186.44(42.80)$ & \\
\hline
\end{tabular}

ECP, eosinophilic cationic protein.

between January and May 1993. Patients with a clinical history suggestive of other respiratory or heart diseases, those with neonatal pathology, and those who had taken systemic or inhaled corticosteroids or cromoglycate in the previous three months were excluded. Thirty eight patients (24 boys and 14 girls) were enrolled. Mean (SD) age at recruitment was $3.08(0.79)$ years.

\section{STUDY DESIGN}

This was an observational study that did not affect usual patient management. On the first visit we recorded clinical data: severity of disease, previous bronchiolitis, parental asthma or atopy, exposure to tobacco, and atopic dermatitis. A prick test was performed with the most common allergens, and a blood sample was obtained for measurement of serum eosinophilic cationic protein, eosinophil count, and total IgE. After this visit the patients were treated according to a standard protocol. ${ }^{7}$ The laboratory results were not communicated to the physician.

The second visit took place in May 1995 (two years after visit 1). The attending physician did not know the results of the medical and laboratory data recorded on the previous visit. We obtained information on the clinical course of the disease, including the need for medical treatment. A prick test was done, a new blood sample was obtained to repeat the above determinations, and in patients who were able to cooperate spirometry was performed. We classed children as persistent wheezers if they had had at least one wheezing episode over the past six months (autumn and winter) or if they had cough or dyspnoea with exercise (group 1, persistent wheezers). The second group were children who had been asymptomatic during the past six months (group 2, transient wheezers).

Table 2 Characteristics of persistent wheezers (group 1) and transient wheezers (group 2) at visit 2

\begin{tabular}{llll}
\hline & Group $1(n=20)$ & Group $2(n=18)$ & p value \\
\hline Positive prick test & $7 / 20$ & $3 / 18$ & 0.1 \\
Total IgE (IU/ml) & $102.87(31.79)$ & $119.68(56.3)$ & \\
Serum ECP $(\mu \mathrm{g} / \mathrm{l})$ & $35.31(7.73)$ & $17.02(2.38)$ & 0.01 \\
Total eosinophils & $491.25(86.78)$ & $256.87(49.18)$ & 0.01 \\
FEV $_{1}(\%$ predicted $)$ & $89.62(6.38)$ & $103.11(2.88)$ & 0.08 \\
FEF $_{25-75}(\%$ predicted $)$ & $87.12(13.64)$ & $104.22(6.55)$ & 0.2 \\
\hline
\end{tabular}

Values are expressed as mean (SEM).

ECP, eosinophilic cationic protein.

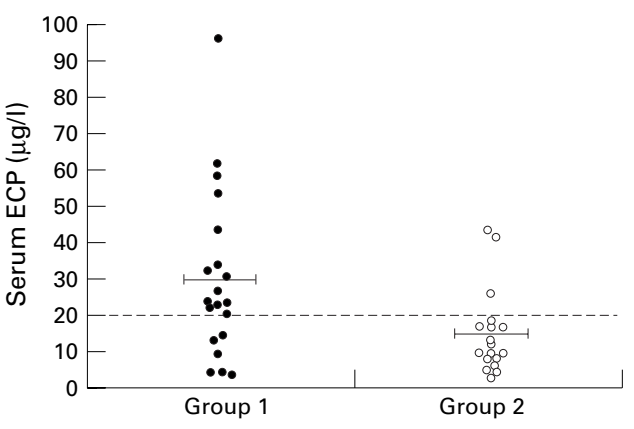

Figure 1 Serum eosinophilic cationic protein (ECP) in group 1 (persistent wheezers) and group 2 (transient wheezers). Geometric mean concentrations of serum ECP are indicated by black bars. Mean (SEM) ECP concentration in group 1 was 29.63 (5.16) $\mu \mathrm{g} / \mathrm{l}$ and in group 2 was 14.42 (2.77) $\mu \mathrm{g} / \mathrm{l}(p<0.01)$.

\section{LABORATORY ANALYSES}

Blood samples were drawn in Vacutainer SST tubes and, after allowing clotting for one hour, blood was centrifuged for 10 minutes. Serum was freshly frozen and stored at $-20^{\circ} \mathrm{C}$ until analysed. Serum concentrations of eosinophilic cationic protein were measured in duplicate by a commercially available fluorescent immunoassay technique (Pharmacia CAP FEIA), with a detection limit below $0.5 \mu \mathrm{g} / \mathrm{l}$; within assay coefficient of variation was $5.8 \%$, and between assay variation $6.2 \% .^{22}{ }^{23}$ The normal values of eosinophilic cationic protein are $5.5 \mu \mathrm{g} / 1$ in children under 2 years of age, and $14.6 \mu \mathrm{g} / 1$ in children between 4 and 16 years. ${ }^{21} \mathrm{IgE}$ was also measured by fluorescent immunoassay (Pharmacia, Uppsala, Sweden).

Total white blood cell count and total eosinophil count were measured by an automated haematology analyser (Technicon H1, Technicon, New York, USA) in a sample of blood containing EDTA.

PRICK TESTS

Patients were tested by the skin prick method with the most common allergens in our area: Dermatophagoides pteronyssinus, Dermatophagoides pharinae, Alternaria tenuis, cladosporium, grass pollen mixture, Olea europea pollen, cat, dog, and horse; negative control was saline and positive control histamine. The extracts used were from ALK (Hørsholm, Denmark). After 20 minutes, the size of the wheal elicited by each allergen was recorded as the mean of two diameters at right angles to each other (in millimetres). Wheal sizes equal to or greater than that obtained with histamine where considered positive. Subjects were considered atopic if they had at least one positive skin test to aeroallergens.

PULMONARY FUNCTION

Lung function was measured in cooperative children, and we rejected measurements that were unreliable. We were able to perform a reliable pulmonary function test in eight children from group 1 and in nine from group 2 . Forced vital capacity (FVC), forced expiratory volume in one second $\left(\mathrm{FEV}_{1}\right)$, and maximum mid-expiratory flow $\left(\mathrm{FEF}_{25-75}\right)$ were measured using a calibrated pneumotachograph system (Jaeger MasterScreen Pneumo; 


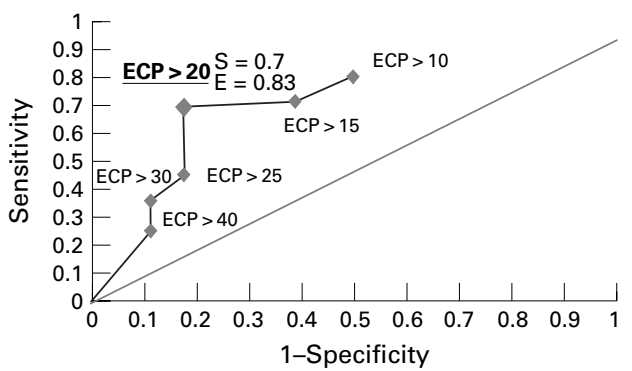

Figure 2 Receiver operating curve (ROC) with the different concentrations of serum eosinophilic cationic protein (ECP) at visit 1 with the sensitivity and specificity for predicting persistent wheezing. The best level to predict persistent wheezing is an ECP of $\geqslant 20 \mu \mathrm{g} / \mathrm{l}$, with a sensitivity of $70 \%$, a specificity of $83.3 \%$, positive predictive value of $82.4 \%$, and negative predictive value of $71.4 \%$.

Jaeger, Wuerzburg, Germany) according to standardised guidelines, the best of three measurements being used for analysis. The data are expressed as percentages of expected values.

\section{ANALYSES}

All statistical analyses were carried out using the Epi Info v 6.1 (CDC and WHO) programs and procedures. The data were analysed by the Student's $t$ test on means, and in cases where Bartlett's test for homogeneity of variance resulted in a $\mathrm{p}$ value $<0.05$ the non-parametric Kruskal-Wallis test was used. Fisher's exact test was used to compare differences in the percentages of patients with the various markers between children with persistent wheezing and those with transitory wheezing. Values of $\mathrm{p}<0.05$ or less were considered significant. Numerical values are expressed as mean (SEM).

\section{Results}

All the children initially selected were followed for two years. Twenty children continued with wheezing episodes on visit $2(52.63 \%)$ (group 1 , persistent wheezers), while 18 remained asymptomatic (group 2, transient wheezers). Clinical and laboratory characteristics of the two groups during visit 1 are shown in table 1 . At visit 1 the only differences between the groups were a larger number of asthmatic mothers in group 1 (four of 20) than in group

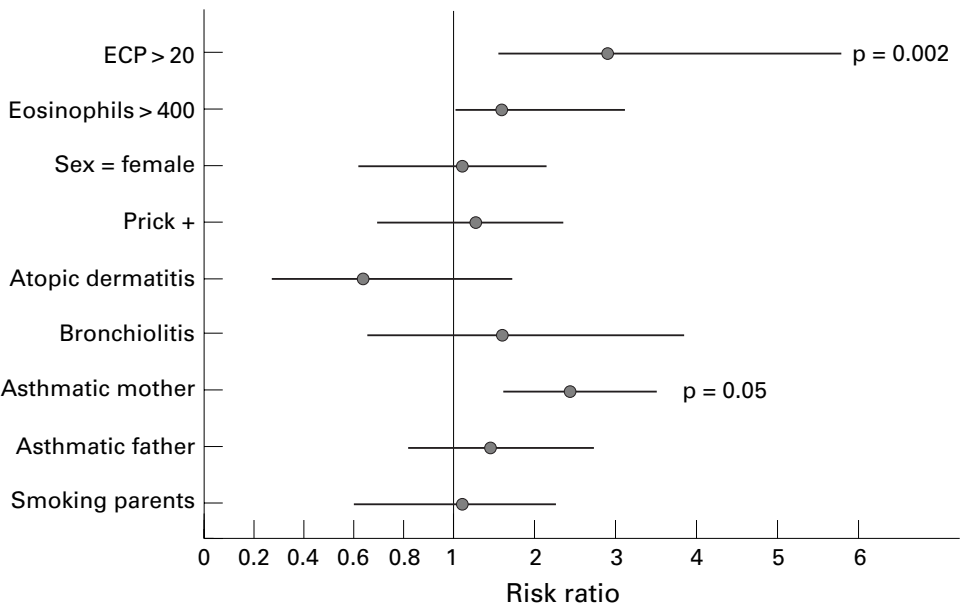

Figure 3 Risk factors at visit 1 for persistent wheezing at visit 2 .
2 (none of 18 ) ( $p=0.05$; single tailed on Fisher's test), and higher eosinophilic cationic protein concentrations in group 1 than in group 2: 29.63 (5.16) v $14.42(2.77) \mu \mathrm{g} / \mathrm{l}, \mathrm{p}<0.01$ (fig 1). The total blood eosinophil count on visit 1 was also higher in group 1, at 358.36 (90.07) $v$ 186.44 (42.80), but the difference was not significant $(\mathrm{p}=0.09)$.

Results of the tests performed on the second visit are shown in table 2 . There was a significant difference between the two groups for serum eosinophilic cationic protein (group $1,35.31(7.73) \mu \mathrm{g} / 1 v$ group $2,17.02(2.38) \mu \mathrm{g} /$ $1 ; \mathrm{p}<0.01$ ) and total eosinophil count (group 1, 491.25 (86.78) v group 2, 256.87 (49.18); $\mathrm{p}<0.01)$.

The children in group 1 had a lower $\mathrm{FEV}_{1}$ and $\mathrm{FEF}_{25-75}$ than children in group 2 (table 2), but the difference was not significant.

We analysed the cut off point for serum eosinophilic cationic protein on the first visit that best predicted which children were going to continue wheezing after two years. Figure 2 shows a receiver operating curve (ROC) representing sensitivity and specificity of the test with eosinophilic cationic protein concentrations of $10,15,20,30$, and $40 \mu \mathrm{g} / 1$. The most advantageous cut off point was $20 \mu \mathrm{g} / \mathrm{l}$, with a sensitivity of $70 \%$, a specificity of $83 \%$, a positive predictive value of $82.4 \%$, and a negative predictive value of $71.4 \%$.

Of all the variables analysed on visit 1 , the only ones with a significant risk ratio (RR) capable of predicting which children will continue to wheeze at visit 2 were an asthmatic mother $(\mathrm{RR}=2.2,95 \%$ confidence interval 1.51 to $3.20 ; \mathrm{p}=0.05)$ and eosinophilic cationic protein $\geqslant 20 \mu \mathrm{g} / 1$ on visit 1 $(\mathrm{RR}=2.88,95 \%$ confidence interval 1.42 to 5.87; $\mathrm{p}<0.001$ (fig 3 ).

\section{Discussion}

The degree to which eosinophil mediated inflammation is involved in young children with asthma and the extent to which such inflammation will determine the prognosis remain unknown. We have studied serum eosinophilic cationic protein as an eosinophil mediated inflammation marker and attempted to correlate this marker with the children's clinical course over two years.

The proportion of children who continued wheezing at age 5 years was $52.6 \%$, higher than in other studies, ${ }^{8}$ but our sample was preselected as the children had been sent to a referral centre for study. Serum eosinophilic cationic protein at age 3 years was 22.48 (3.23) $\mu \mathrm{g} / \mathrm{l}$, similar to the value published by Ingram et al for a group of wheezing children aged 2 to 4 years. ${ }^{21}$ These serum concentrations were higher than those found in the general population. ${ }^{23}$ However, the concentrations measured in our study cover a very wide range, suggesting that there may be two distinct groups of children, one with eosinophil mediated inflammation and another where inflammation does not play an important role in wheezing (fig 1).

We have tried to correlate serum eosinophilic cationic protein values with the clinical course 
in these children. We found that children with high serum eosinophilic cationic protein $(\geqslant 20 \mu \mathrm{g} / \mathrm{l})$ had a significantly increased risk of persisting asthma two years after the determination; very few children in this category (only three of 17) remained asymptomatic by visit 2 . A few children (six of 20) with low serum eosinophilic cationic protein continued to be symptomatic after two years. This could reflect an insufficient follow up time-some children with transitory disease may continue to be symptomatic after two years.

The Tucson study ${ }^{8}$ showed that children with transient wheezing are born with abnormal pulmonary function, while those with persistent wheezing are born with normal pulmonary function. It has been suggested that children with transient wheezing suffer from this symptom because they are born with abnormally small airways, which predisposes them to airway obstruction with viral infections. ${ }^{24}$ We have been able to show that our persistent wheezers had high serum eosinophilic cationic protein, which could reflect an eosinophil mediated inflammatory bronchial process from the onset, in contrast with children with transitory wheezing who do not seem to have this bronchial inflammation. It is likely that only the persistent wheezer group has inflammatory asthma, while the other group has anatomically determined wheezing (smaller airway size).

In our study, children with transitory wheezing had normal pulmonary function at age 5-6 years, while the persistent wheezers had abnormal pulmonary function. This difference was not significant owing to the small number of cases in which pulmonary function could be evaluated because of the children's young age. In the study by Martinez et $a l^{8}$ at age 6 years both transient and persistent wheezers had abnormal pulmonary function. Transient wheezers in that study already had abnormal pulmonary function at birth, while the persistent wheezers had normal function at birth that deteriorated with age, perhaps reflecting the deleterious effect of the chronic disease on the bronchi. Henderson et al also found a deterioration in lung function in children with a history of recurrent wheezing before the age of 6 years who were sensitised to house dust mites. ${ }^{25}$ Chronic allergic inflammation of the airways may be responsible for these changes.

Some investigators have suggested that a higher serum IgE value during the first year of life can predict which children will continue wheezing, ${ }^{86}$ but we did not find higher IgE concentrations in the persistent wheezer group.

It is now suggested that early treatment of bronchial inflammation from the onset of the disease may arrest its progress. ${ }^{27}$ Most asthmatics start developing symptoms at age $2-3$ years, but $60 \%$ of wheezing children at this age will be asymptomatic when they are 6 years old, so it would be of interest to know which children have a transitory disease and which have early childhood asthma. The latter group would probably benefit from anti-inflammatory drug treatment. There is controversy over the effectiveness of anti-inflammatory treatment for asthma in this age group, and not all studies have shown that inhaled corticosteroids affect the clinical course of the disease. This may reflect the heterogeneous nature of the cases sampled, as in many of these children wheezing may not be related to an inflammatory process.

\section{CONCLUSION}

Our findings suggest that eosinophilic inflammation is present from the onset of the disease in the group of wheezing young children who are going to continue with wheezing episodes at age 5-6 years. Determination of serum eosinophilic cationic protein, along with evaluation of other factors such as family history, may help to determine which children will continue with asthma and could therefore benefit from a more aggressive approach to treatment, and which children merit a more conservative approach as their disease will probably be transitory. Studies with more patients and a longer follow up period are needed to confirm these results.

1 International Consensus Report on Diagnosis and Management of Asthma. Allergy 1992;47(suppl 13):1-61.

2 Holgate ST. The role of inflammatory processes in airway hyperresponsiveness. Oxford: Blackwell, 1989.

3 Barnes P. A new approach to the treatment of asthma. $N$ Engl f Med 1989;321:1517.

4 Barnes PJ. Inhaled glucocorticoids for asthma. $\mathrm{N} \mathrm{Engl} 7 \mathrm{Med}$ 1995;332:868-75.

5 Ferguson AC, Wong FWM. Bronchial hyperresponsiveness in asthmatic children. Correlation with macrophages and eosinophils in broncholavage fluid. Chest 1989;96:988-91. 6 Larsen G. Inflammation and immunopathology. Am $\mathcal{F}$ Respir Crit Care Med 1995;151:13-14.

7 Asthma: a follow up statement from an international paediatric asthma consensus group. Arch Dis Child 1992;67: $240-8$.

8 Martinez FD, Wright AL, Taussig LM, Holberg CJ, Halonen M, Morgan WJ. Asthma and wheezing in the first six years of life. N Engl f Med 1995;332:133-8.

9 Burrows B, Martinez F, Halonen M, Barbee RA, Cline MG. Association of asthma with serum IgE levels and skin-test reactivity to allergens. N Engl f Med 1989;20:271-7.

10 Zimmerman B, Feanny S, Reisman J, et al. Allergy in asthma. I. The dose relationship of allergy to severity of childhood asthma. F Allergy Clin Immunol 1988;81:63.

11 Bisgaard H, Munck SL, Nielsen JP, et al. Inhaled budesonide for treatment of recurrent wheezing in early childhood. Lancet 1990;336:649-51.

12 Holt PG. A potential vaccine strategy for asthma and allied atopic diseases during early childhood. Lancet 1994;344: $456-8$

13 Taussig LM. The conundrum of wheezing and airway hyperreactivity in infancy. Pediatr Pulmonol 1992;13:1-3.

14 Venge P. Soluble markers of allergy inflammation. Allergy 1994;49:1-8.

15 Ahlstedt S, Enander Y, Peterson CGB, Lanner A. The clinical assessment of the inflammatory component in asthma with emphasis on the eosinophils. Pract Allergy Immunol 1992;3:149-54.

16 Adelroth E, Rosenhall L, Johansson SA, Linden M, Venge P. Inflammatory cells and eosinophilic activity in asthmatics investigated by bronchoalveolar lavage: the effects of investigated by bronchoalveolar lavage: the effects of Am Rev Respir Dis 1990;142:91-9.

17 Rao R, Frederick JM, Enander I, Gregson RK, Warner JA, Warner JO. Airway function correlates with circulating Warner JO. Airway function correlates with circulating childhood asthma. Clin Exp Allergy 1996;26:789-93.

18 Griffin E, Hakanson L, Foringren H, Jörgensen K, Peterson $\mathrm{C}$, Venge P. Blood eosinophil number and activity in relation to lung function in asthmatic patients with eosinophilia. f Allergy Clin Immunol 1991;87:548-57.

19 Sugai T, Sakiyama Y, Matumoto S. Eosinophil cationic protein in peripheral blood of pediatric patients with allergic diseases. Clin Exp Allergy 1992;22:275-81.

20 Zimmerman B. Clinical experience with the measurement of eosinophilic cationic protein: usefulness in the management of children with asthma. Clin Exp Allergy 1993; 23(suppl 2):8-12.

21 Ingram JM, Rakes GP, Hoover GE, Platts-Mills TAE, Heymann PW. Eosinophil cationic protein in serum and nasal washes from wheezing infants and children. Pediatr 1995;127:558-64.

22 Ahlstedt S, Enander Y, Peterson CGB, Lanner A. The clinical assessment of the inflammatory component in asthma with emphasis on the eosinophils. Pract Allergy Immunol 1992;3:149-54. 
23 Peterson CGB, Enander I, Nystrand J, Anderson AS, Nilsson L, Venge P. Radioimmunoassay of human eosinophil cationic protein (ECP) by an improved method. Establishment of normal levels in serum and turnover in vivo. Clin Exp Allergy 1991;21:561-7.

24 Martinez FD, Morgan WJ, Wright AL, et al. Diminished lung function as a predisposing factor for wheezing respiratory illness in infants. N Engl F Med 1988;319:1112-17.

25 Henderson FW, Stewart PW, Burchinal MR, et al. Respiratory allergy and the relationship between early childhood lower respiratory illness and subsequent lung function. $A m$ Rev Respir Dis 1992;145:283-90.

26 Rowntree S, Antognoni JJ, Platts-Mills TAE, Mitchel EB. Development of IgE and IgG antibodies to food and inhalant allergens in children at risk of allergic disease. Arch Dis Child 1985;60:727-35.

27 Pedersen S, Agertoft L. Effect of long term budesonide treatment on growth, weight and lung function in children with asthma [abstract]. Am Rev Respir Dis 1993; 147(suppl):A265.

\section{Ethics, emotions, and meningococcaemia}

It is by no means a new problem but does it have an answer? You are faced with a child who is desperately ill and may well die. You have a new potential treatment that has not been submitted to a controlled trial but preliminary reports suggest it might appreciably reduce the risk of death or morbidity. Do you go ahead with random assignment to new treatment or placebo, or do you do what you almost certainly would do if it were your own child and give the treatment? But you don't know whether the treatment could in fact be harmful; of course you don't, but in those circumstances you would probably be prepared to take the risk. So how do you prove new treatments and how do you get truly informed consent for randomised trials?

Two recent reports about treatment for severe meningococcal septicaemia illustrate the problem. The first (Giroir and colleagues; Lancet 1997;350:1439-43) concerned the use of $\mathrm{rBPI}_{21}$, a recombinant, $\mathrm{N}$-terminal fragment of human bactericidal/permeability increasing protein, which binds endotoxin and kills meningococci. Twenty six patients were treated and one died. Between four and eight deaths might have been expected. Nevertheless it has been suggested that the treatment was given too late for it to be reasonable to suppose that $\mathrm{rBPI}_{21}$ had an appreciable effect on endotoxin or cytokine levels (commentary, Lancet 1997;350:1565-6). A multinational randomised trial has been set up. The second report, from Dublin, (Smith and colleagues; Lancet 1997;350:1590-3) details the results of giving a mixture of three new treatments. Twelve patients were treated for meningococcal septicaemia with purpura fulminans and severe acquired protein $\mathrm{C}$ deficiency. All 12 were given intravenous protein $\mathrm{C}$, 11 were given heparin, and nine had haemodiafiltration. No patient died although the predicted mortality was $57-80 \%$. The authors call for a randomised trial.

I don't know the answers. How do you obtain truly informed consent? Is it ethical not to tell parents about the results of the preliminary trials or do you simply say, no trial, no treatment? In a condition with high mortality would it be wrong to continue with a trial using historical controls? Supposing, for instance, the Irish trial were to continue uncontrolled and after 25 , or 50 , or 100 patients there were still no deaths and morbidity remained low, wouldn't that be convincing, and wouldn't it have avoided inevitable deaths in a controlled trial? But if the results became less clear cut wouldn't that then provide an even stronger indication for a randomised trial? Perhaps somebody out there will explain.

ARCHIVIST 